\section{Cranberry Yield and Fruit Quality Reduction Caused by Weed Competition}

\author{
Kim D. Patten ${ }^{1}$ and John Wang ${ }^{2}$ \\ Washington State University, Long Beach Research and Extension Unit, Long \\ Beach, WA 98631
}

Additional index words. Vaccinium macrocarpon, Potentilla pacifica, Aster subspicatus, Lotus corniculatus, photosynthetic active radiation, weed interference

Abstract. The relationships between canopy density of three perennial weed species (Potentilla pacifica Howell,Aster subspicatus Nees, and Lotus corniculatus L.) and 'Mcfarlin' and 'Stevens' cranberry (Vaccinium macrocarpon Ait.) yield and fruit quality were evaluated. Yield was more severely affected by weed interferences than fruit size or color. Best-fit regression equations for the effects of weed density on yield, fruit size, and color were linear or quadratic polynomials with a strong linear component. For each bog, the slope of the linear relationship between yield and weed density was more negative as the mean yield of weed-free controls increased. 'Stevens' fruit size and yield were more sensitive and fruit color was less sensitive to changes in $P$. pacifica population density than those of 'McFarlin'.

The prostrate growth habit of cranberries and the inability to use mechanical weed control make cranberries prone to weed competition. The potential production loss, estimated to be from $15 \%$ (Chandler et al., 1984) to $25 \%$ (Swanton et al., 1993), of cranberries due to weeds is among the highest of any agricultural commodity. Three herbaceous perennial weeds in western North America are particularly damaging to cranberries: Potentilla pacifica (Pacific silverleaf), Lotus corniculatus (Birdsfoot trefoil), and Aster subspicatus (Douglas aster). These weeds are fecund and difficult to control with available herbicides. Few studies, however, have documented the impact of specific weed populations on cranberry production. In studies comparing weedy to nonweedy bogs, the yield components most reduced by weeds were upright density, percentage of flowering uprights, flowers per upright, and fruit set (Hicks et al., 1968; Yas and Eaton, 1982).

Competition for light seems to be the major factor accounting for yield suppression by weeds (Aldrich, 1984). Shading of cranberries, especially postbloom, reduces fruit set, yield, and upright structural and nonstructural carbohydrates (Roper et al., 1993). Shading of other Ericaceae decreased flower bud formation and shoot density and weight (Hall, 1958; Iason and Hester, 1993).

Received for publication 4 Oct. 1993. Accepted for publication 10 May 1994. College of Agriculture and Home Economics Research Center, Washington State Univ., Pullman, H/LA Paper no. 93-20 and Project no. 6090. The cost of publishing this paper was defrayed in part by the payment of page charges. Under postal regulations, this paper therefore must be hereby marked advertisement solely to indicate this fact.

${ }^{1}$ Associate Horticulturist

${ }^{2}$ Research Technician.
Our objectives were to 1) quantify the relationship of cranberry yield and fruit quality with the population of three perennial weeds and 2) evaluate the response of two different cranberry cultivars to weed interferences.

\section{Materials and Methods}

Cranberry bogs in Long Beach, Wash., were selected in 1991 and 1992 with varying Potentilla pacifica, Lotus corniculatus, and Aster subspicatus populations. Cranberry plantings that had a uniform cranberry vine density and a wide range of weed population densities were chosen. Each experimental unit was a circle, $\approx 1 \mathrm{~m}$ in diameter, containing a relatively uniform weed canopy density across the plot. Each site was paired with an adjacent weed-free control. Potentilla pacifica was monitored from 60 sites across eight separate 'McFarlin' bogs in 1991, 77 sites across four 'Mcfarlin' bogs in 1992, and 25 sites in one 'Stevens' bog in 1992. Aster subspicatus was monitored from 48 and 37 sites across two bogs in 1991 and 1992, respectively. Lotus corniculatus was monitored in 36 sites across two bogs in 1992. Weed canopy density was evaluated at each site at the period of maximum weed density (early Sept.) by measuring weed canopy interception of photosynthetic active radiation (PAR) with a ceptometer (Decagon, Pullman, Wash.). Midday PAR readings were taken on sunny days along a 1-m plane above the weed canopy and at the interface between the top of the cranberry canopy and the bottom of the weed canopy. Ten ceptometer readings were taken across different radial transects of each weed site to obtain an average PAR for the bottom of the weed canopy. Data were converted to the percentage of total PAR absorbed by the weed canopy. Weed fresh and dry weight from a $0.072-\mathrm{m}^{2}$ area within the sampling site and a

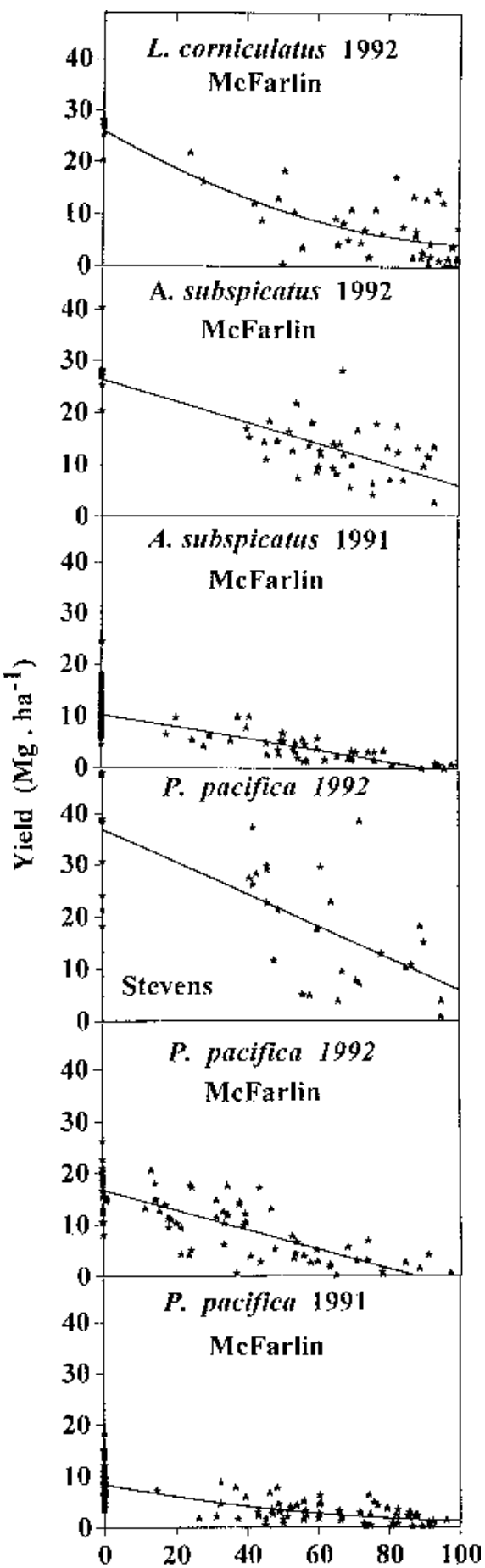

Light absorbed by weed canopy ("\% of total PAR)

Fig. 1. Relationship between cranberry yield at Long Beach, Wash., and the percentage of total sunlight (photosynthetic active radiation) absorbed by various weed canopies. The best-fit linear or nonlinear regression equations for the effect of light absorbed by weed canopy on yield were $\mathrm{y}=-0.22 \mathrm{x}+24, r^{2}=0.7 ; \mathrm{y}=-0.21 \mathrm{x}+26$, $r^{2}=0.58 ; \mathrm{y}=-0.11 \mathrm{x}+10, r^{2}=0.61 ; \mathrm{y}=-0.3 \mathrm{x}+$ $35, r^{2}=0.53 ; \mathrm{y}=-0.19 \mathrm{x}+17, r^{2}=0.62 ; \mathrm{y}=$ $0.0006 \mathrm{x}^{2}-0.13 \mathrm{x}+8.4, r^{2}=0.56$ for $L$. corniculatus 1992 on McFarlin, A. suspicutus 1992 and 1991 on McFarlin, P. pacifica 1992 on Stevens, and P. pacifica on McFarlin in 1992 and 1991, respectively. 


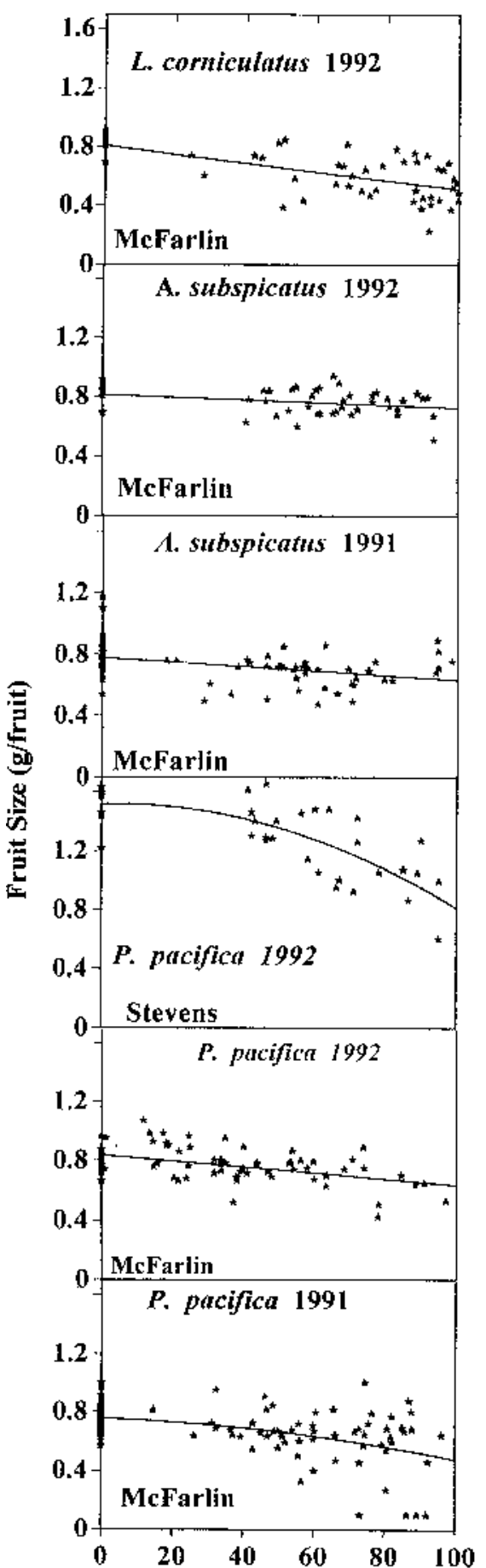

Light absorbed by weed canopy ( $\%$ of total PAR)

Fig. 2. Relationship between cranberry fruit size at Long Beach, Wash., and the percentage of total sunlight (photosynthetic active radiation) absorbed by various weed canopies. The best-fit linear or nonlinear regression equations for the effect of light absorbed by weed canopy on fruit size were $\mathrm{y}=-0.003 \mathrm{x}+0.81, r^{2}=0.38 ; \mathrm{y}=$ $-0.0008 \mathrm{x}+0.81, r^{2}=0.75 ; \mathrm{y}=-0.0015 \mathrm{x}+0.78$, $r^{2}=0.17 ; \mathrm{y}=-0.00008 \mathrm{x}^{2}+0.0001 \mathrm{x}+1.5, r^{2}=$ $0.55 ; \mathrm{y}=-0.002 \mathrm{x}+0.84, r^{2}=0.24 ; \mathrm{y}=-0.00002 \mathrm{x}^{2}$ $-0.0007 \mathrm{x}+0.75, r^{2}=0.23$ for L. corniculatus 1992 on McFarlin, A. suspicutus 1992 and 1991 on McFarlin, P. pacifica 1992 on Stevens, and P. pacifica on McFarlin in 1992 and 1991, respectively. visual rating of crop canopy covered by weeds (percent) also were recorded. In late September to early October, two subsamples of fruit were picked within each sampling site $(0.018$ $\mathrm{m}^{2}$ each). Yield and average fruit weight were recorded. In 1992, average fruit color at harvest and percent fruit rot after 1 month of storage at $5 \mathrm{C}$ were measured for all samples. Fruit color was determined by placing each fruit from the sample in one of five color categories $(1=$ green, 3 = light red, $5=$ very dark red). The number of fruit in each category was multiplied by its rating number and an overall average was determined. Linear and nonlinear regression analysis (SAS Institute, 1985) were used to determine the best-fit relationship between yield and fruit quality characteristics and weed density. Analysis was done as a function of absolute yield, using the weed-free site as discrete datum, and as a percentage of change compared to the matched weed-free site. In some instances, extreme outliers were obtained for percent change values due to an errant value for the weed-free sample. Corrections were made by using an average value for all weed-free sites within the bog.

\section{Results and Discussion}

For all measurements tested, the best-fit regression equations, as evaluated by coefficients of determination $\left(r^{2}\right)$, were always better when weed population data were presented as a function of the percentage of total PAR absorbed by weed canopy, rather than weed fresh or dry weight or a rating of percent weed coverage (data not shown). Regression equations of better fit also were found when the data were presented in absolute values rather than percent change relative to weed-free control values (Fig. 1-3 vs. Table 1). In general, based on the slope of the linear regression line for percent change compared to the weed-free control, yield was more severely affected by weed interference than fruit size or color (Table 1). For the one bog examined, yield and fruit size of 'Stevens' seemed to be more sensitive and fruit color less sensitive than that of 'McFarlin' to changes in $P$. pacifica population density. There was no significant relationship between weed populations and fruit rot (data not shown).

When compared across all weed species, cultivars, and years, the slope of the best-fit regression line for the effects of weed density on yield was more negative as the mean yield of weed-free controls increased (Fig. 4). This result indicates that yield loss in high-yielding cranberry beds may be reduced more by weed competition than in low-yielding cranberry beds. Across the weed density ranges evaluated in these studies, there did not seem to be a well-defined inflection point that signified a specific limiting threshold value for light (Fig. $1)$. Instead, there seemed to be a linear continuum. With some exceptions, the decline in fruit size and color with weed coverage was also linear (Figs. 2 and 3). Quadratic polynomials equations, however, accounted for the most variation in 'McFarlin' fruit size in 1991 and in that of 'Stevens' in 1992 with increases in P. pacifica coverage (Fig. 2). Quadratic polynomials also accounted for the most variation in 'McFarlin' fruit color with increasing L. corniculatus or P. pacifica densities (Fig. 3). Some red fruit pigmentation continued at the highest weed densities of all three species, with the exception of a few $L$. corniculatus samples.

The overall relative insensitivity of fruit size to shading has been reported for cranberries (Roper et al., 1993; Yas and Eaton, 1982) and lowbush blueberry (Vaccinium angustifolium Ait.) (Yarborough and Bhowmik, 1993). Fruit size may be compensated under shade due to an indirect effect of

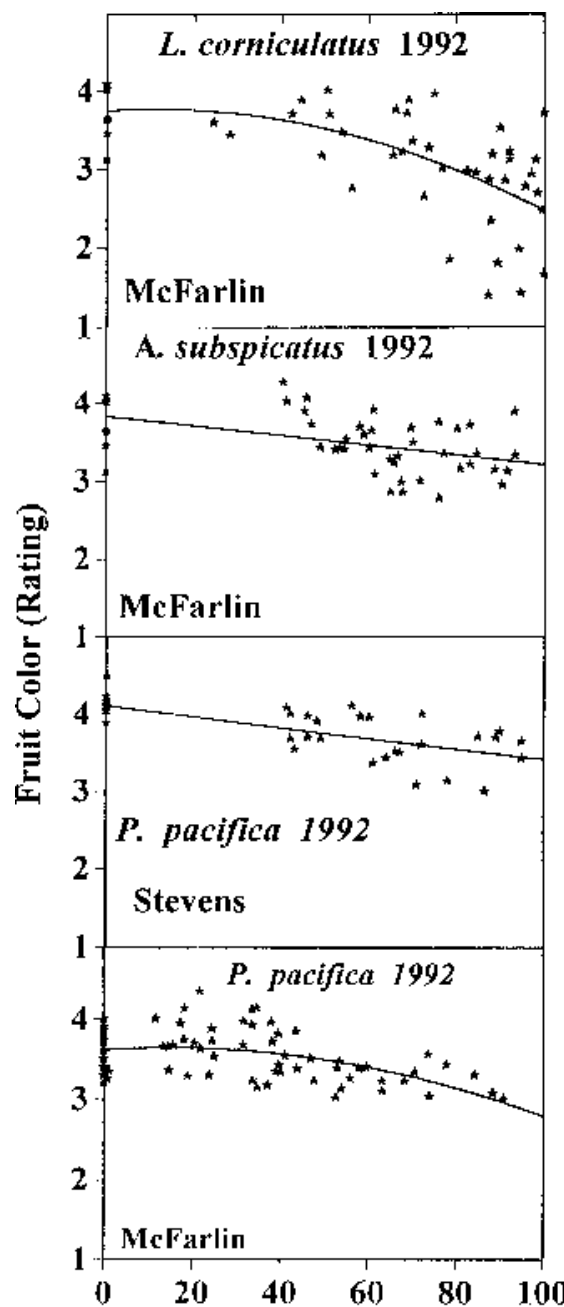

Light absorbed by weed canopy (\% of total PAR)

Fig. 3. Relationship between cranberry fruit color at Long Beach, Wash., and the percentage of total sunlight (photosynthetic active radiation) absorbed by various weed canopies. (Fruit color rating: $1=$ green, $3=$ light red, $5=$ very dark red.) The best-fit linear or nonlinear regression equations for the effects of light absorbed by weed canopy on fruit color rating were $\mathrm{y}=-0.00016 \mathrm{x}^{2}+0.003 \mathrm{x}+3.7, r^{2}$ $=0.4 ; \mathrm{y}=-0.0021 \mathrm{x}+3.8, r^{2}=0.22 ; \mathrm{y}=-0.007 \mathrm{x}+$ $4.1, r^{2}=0.61 ; \mathrm{y}=0.00012^{2}+0.0034 \mathrm{x}+3.6, r^{2}=0.23$ for $L$. corniculatus on McFarlin, A. suspicutus on McFarlin, P. pacifica on Stevens, and P. pacifica on McFarlin, respectively. 
Table 1. Percent decrease (linear) in cranberry yield and fruit quality compared to weed-free control as a function of the percentage of total photosynthetic active radiation intercepted by weed canopy.

\begin{tabular}{|c|c|c|c|c|c|c|c|c|c|}
\hline \multirow[b]{2}{*}{ Weed } & \multirow[b]{2}{*}{ Cultivar } & \multirow[b]{2}{*}{ Year } & \multirow[b]{2}{*}{ df } & \multicolumn{2}{|c|}{$\%$ Yield loss } & \multicolumn{2}{|c|}{$\%$ Fruit color decrease } & \multicolumn{2}{|c|}{$\%$ Fruit size decrease } \\
\hline & & & & Slope & $r^{2 z}$ & Slope & $r^{2}$ & Slope & $r^{2}$ \\
\hline \multirow[t]{3}{*}{ Potentilla pacifica } & McFarlin & 1991 & 60 & -0.77 & 0.36 & --- & --- & -0.60 & 0.25 \\
\hline & McFarlin & 1992 & 77 & -0.68 & 0.46 & -0.71 & 0.40 & -0.39 & 0.37 \\
\hline & Stevens & 1992 & 25 & -0.96 & 0.44 & -0.17 & 0.21 & -0.66 & 0.48 \\
\hline \multirow[t]{2}{*}{ Aster subspicutus } & McFarlin & 1991 & 48 & -0.84 & 0.52 & --- & --- & -0.19 & NS \\
\hline & McFarlin & 1992 & 37 & -0.44 & 0.35 & -0.20 & 0.20 & -0.06 & NS \\
\hline Lotus corniculatus & McFarlin & 1992 & 36 & -0.58 & 0.32 & -0.47 & 0.30 & -0.21 & NS \\
\hline
\end{tabular}

${ }^{\mathrm{z}}$ Only $r^{2}$ with $P>0.05$ are presented.

Ns Nonsignificant at $P \leq 0.05$.

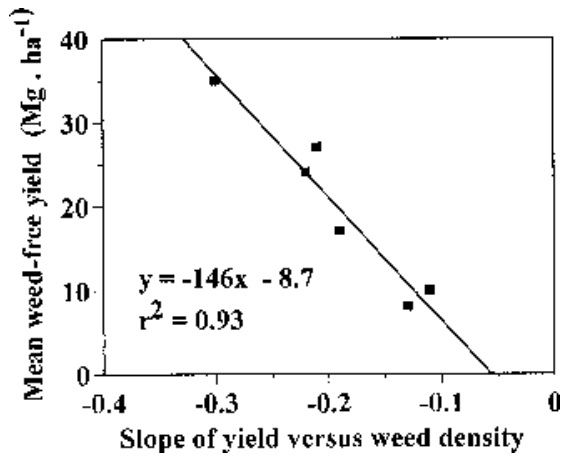

Fig. 4. Change in slope of the linear regression between yield and weed density as a function of the mean yield of the bog at the zero weed level. Data collected across cultivars, years, and weed species.

shade lowering fruit temperatures and increasing turgor potential (Crippen and Morrison, 1986) or due to redirected resources within fruiting uprights (Shawa et al., 1981). Because color had a relatively low sensitivity to weed density, except in cases of extreme canopy shading, it seems that exposure of fruit to light was adequate to obtain at least some level of red pigmentation.

Our research addressed only the impact of full-season interference from weeds. Cranberries, however, may be especially sensitive to interference from weeds during a specific phenologic period. For example, fruit set is important in accounting for yield variation (Eaton and Kyte, 1978; Shawa et al., 1981) and seems to be carbohydrate-resource limiting. Shading by weeds after pollination could restrict carbohydrates required for fruit set. In artificial shading experiments on cranberries, Roper et al. (1993) found that $93 \%$ shading during the postbloom period had a more severe impact on fruit set than shading during the prebloom or preharvest period. Even more important than carbohydrate resources may be that canopy coverage by weeds during bloom (June) likely restricts pollinator access to flowers, thus limiting pollination and fruit set (Birrenkott et al., 1992). If the shading interval is critical, then the time that the weed canopy develops becomes important.

Field observation indicates that $P$. pacifica and $L$. corniculatus, depending on vigor, may either partially occlude or completely occlude light from a cranberry canopy during bloom (June). The L. corniculatus canopy density continues to increase rapidly throughout the growing season compared to the more gradual development of P. pacifica. Aster subspictus does not reach full canopy development until August; therefore, it causes less early season shading than the other two species. It was not unusual, however, to find extreme variability in weed density effects on yields. For example, good cranberry yields were obtained with $L$. corniculatus plots in areas where $80 \%$ to $95 \%$ of the total PAR was absorbed by the weed canopy (Fig. 1). These anomalous values were most likely from areas where the majority of the weed canopy developed after pollination. This relationship suggests that weed control measures that delay or suppress early weed canopy development might be useful for minimizing short-term yield losses due to weeds.

Competition between weeds and cranberries for water or nutrients is usually minimal under normal growing practices. If the latter were limiting or if allelopathic effects were apparent, then weed fresh weight could be expected to be more related to yield loss than canopy shading. Therefore, competition for light is likely a strong determining factor by which weeds limit cranberry yield. This supposition is reasonable because the light saturation for photosynthesis in cranberries is relatively high $\left(1200 \mu \mathrm{mol} \cdot \mathrm{m}^{-2} \cdot \mathrm{s}^{-1} \mathrm{PAR}\right)$ (Hagidimitriou, 1993), and the midday, fullsun, PAR values for coastal Washington are around $1350 \mu \mathrm{mol} \cdot \mathrm{m}^{-2} \cdot \mathrm{s}^{-1}$. A small amount of shading, therefore, could be expected to affect yield markedly.

The relationship between the light absorbed by the weed canopy and the weed fresh weight was different for each weed species (Fig. 5). For a given level of shading by the weed canopy, P. pacifica had the lowest fresh weight and $L$. corniculatus had the highest. This relationship seems sensible based on the weed canopy architecture. Potentilla pacifica is a recumbent stoloniferous rosette plant with leaves extending just over the cranberry canopy. Aster subspictus has a single erect stem that allows some light penetration when the sun is at oblique angles. Lotus corniculatus has a dense recumbent canopy extending 15 to $30 \mathrm{~cm}$ above the cranberry canopy. Our data on canopy shading, however, are based on a single midday light measurement. For weed canopy architectures that provide a greater percentage of light harvesting at low sun angles, such as with $L$. corniculatus, our measurements may undervalue the relative shading effectiveness of a weed.

To make weed management decisions, it is necessary to develop threshold values, above which a weed population is not acceptable (Else, 1992). The cultivar's or particular bog's sensitivity to weed interference is an important consideration. Our data imply that a given weed population has more impact under a high-yield circumstance (e.g., 'Stevens' bog) than under marginal production. The longterm influence of weeds on future crop yield must also be integrated into the threshold value (Maxwell, 1992). In a perennial crop such as cranberries, weed interference affects cropping in future years by influencing yield component factors, such as floral induction and upright density (Yas and Eaton, 1982). The long-term impacts of specific weed populations on cranberry yield cannot be determined easily from our data because of the variability in results between years and the lack of data on the population history of each weed plot. Nevertheless, field observation indicates that areas of a cranberry bog subjected to heavy $L$. corniculatus infestation become void of vines after only a few years, whereas this transition takes considerably longer with $P$. pacifica or A. subspictus. Information on the rate of weed spread and the costs and efficacy of the various control options is also necessary for threshold modeling (Else, 1992). The herbaceous perennial weeds evaluated in this study are difficult to control, and in the case of $L$. corniculatus and $P$. pacifica, they spread quickly. This growth pattern implies that threshold values of zero may be most appropriate.

We found that, in general, weed populations reduced cranberry yield linearly, with competition for light being the most likely limiting factor. Fruit quality attributes were less sensitive than yield to weed interference. Further research is needed to define the critical period(s) of weed interference and long-term effects of weed populations on cranberry yield components.

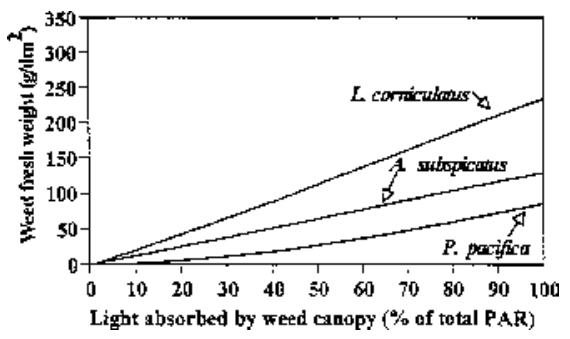

Fig. 5. Relationship between fresh weight of three weeds at Long Beach, Wash., and the percentage of total sunlight (photosynthetic active radiation) absorbed by the weed canopy. 


\section{Literature Cited}

Aldrich, R.J. 1984. Weed-crop ecology. Breton Publishers, N. Scituate, Mass.

Birrenkott, B.A., C.A. Henson, and E.J. Stang. 1991. Carbohydrate levels and the development of fruit in cranberry. J. Amer. Soc. Hort. Sci. 116:174-178.

Chandler, J.M., A.S. Hamill, and A.G. Thomas. 1984. Crop losses due to weeds in Canada and the United States. Special Weed Sci. Soc. Amer. Rpt. 22.

Crippen, D.D. and J.C. Morrison. 1986. The effects of sun exposure on the compositional development of Cabernet Sauvignon berries. Amer. J. Enol. Viticult. 37(4):235-242.

Eaton, G.W. and T.R. Kyte. 1978. Yield component analysis in the cranberry. J. Amer. Soc. Hort. Sci. 103:578-583.

Else, M.J. 1992. Integrated management of weeds in a perennial crop: The example of cranberries. HortScience 27:1163. (Abstr.)

Hagidimitriou, M. 1993. Carbohydrate and photosynthesis in cranberry (Vaccinium macrocarpon Ait.). PhD Diss., Univ. of Wisconsin, Madison.

Hall, I.V. 1958. Some effects of light on native lowbush blueberries. Proc. Amer. Soc. Hort. Sci. 72:216-218.

Hicks, J.L., I.V. Hall, and F.F. Forsyth. 1968. Growth of cranberry plants in pure stands and in weed areas under Nova Scotian conditions. Hort. Res. 8:104-112.

Iason, G.R. and A.J. Hester. 1993. The response of heather (Calluna vulgaris) to shade and nutrients-Predictions of the carbon-nutrient balance hypothesis. J. Ecol. 81:75-80.

Maxwell, B.D. 1992. Weed thresholds: The space component and considerations for herbicide resistance. Weed Technol. 6:205-212.
Roper, T.R., M. Hagidimitriou, and J. Klueh. 1993. Photosynthesis and carbohydrate partitioning in cranberry. Wis. Cranberry School 1993 Proc. 4:18-27.

SAS Institute. 1985. SAS user's guide: Statistics. Version 5 ed. SAS Institute, Cary, N.C.

Shawa, A., G.W. Eaton, and P.A. Bowen. 1981. Cranberry yield components in Washington and British Columbia. J. Amer. Soc. Hort. Sci. 106:474-477.

Swanton, C.J., K.N. Harker, and R.L. Anderson. 1993. Crop losses due to weeds in Canada. Weed Technol. 7:537-542.

Yarborough, D.E. and P.C. Bhowmik. 1993. Lowbush blueberry-bunchberry competition. J. Amer. Soc. Hort. Sci. 118:54-62.

Yas, A.M. and G.W. Eaton. 1982. Effect of cottongrass on the yield components of cranberry. Scientia Hort. 18:125-129. 